\title{
Excretion of myoglobin in urine after cardiac catheterisation
}

\author{
T. G. DONALD, M. J. CLOONAN, AND D. E. L. WILCKEN \\ From the Divisions of Cardiovascular Medicine and Microbiology, Prince Henry Hospital, \\ Little Bay (Sydney), New South Wales, 2036, Australia
}

SUMMARY Myoglobin levels were assayed in each urine specimen voided during 12 hours before and 48 hours after routine cardiac catheterisation in 146 patients using an indirect haemagglutination method detecting concentrations in excess of $0.015 \mathrm{mg} / \mathrm{ml}$. Myoglobinuria was found in only one patient before but in 39 patients after cardiac catheterisation (27\%), either in the first (34 patients) or the second (5 patients) post-catheterisation urine sample. Once detected, myoglobin was present in all subsequent urine specimens for the next 3 to 22 hours (mean 11.8 hours). The mean amount excreted \pm SE was $14.0 \pm 1.6 \mathrm{mg}$ (range 2.6 to $30 \mathrm{mg}$ ) excluding the one patient with myoglobinuria before catheterisation. This patient, who had severe aortic stenosis and atherosclerotic heart disease, excreted 130 mg myoglobin. Patients with myoglobinuria required longer screening time to complete the procedures undertaken than those in whom myoglobin was not detected-15.6 \pm 1.4 and $11.1 \pm 0.6$ minutes, respectively (means \pm SE: $\mathrm{P}<0.01$ ).

We conclude that myoglobinuria is not uncommon after cardiac catheterisation, and that though the myoglobin detected may be released from skeletal muscle, it could be partly or wholly of cardiac origin and indicate transient, and presumably reversible, myocardial injury.

When muscle is damaged it releases myoglobin into the bloodstream and this is then rapidly excreted in the urine (Kagen, 1973). We have recently developed a simple and sensitive assay for urinary myoglobin (Cloonan et al., 1976) and have used it to quantify myoglobinuria after acute myocardial infarction (Donald et al., 1977). In the course of evaluating the significance of myoglobinuria, we sought evidence for this after a number of cardiovascular investigations. We report here the unexpected finding of substantial amounts of myoglobin in the urine in 27 per cent of patients undergoing cardiac catheterisation.

\section{Subjects and methods}

Investigations were done on 146 patients coming to routine cardiac catheterisation to test for myoglobinuria during the 12 hours before and the 48 hours after the procedure. The diagnoses are shown in Table 1. The volume of each urine specimen voided was recorded and aliquots of each specimen were immediately frozen at $-20^{\circ} \mathrm{C}$ and later tested for the presence of myoglobin using an indirect haemagglutination method. With this method, the presence of myoglobin in the urine is detected by inhibition of agglutination of sensitised red blood cells; myoglobin reacts with the specific antibody before the addition of the cells. The method detects a minimum myoglobin concentration of $0.02 \mathrm{mg} / \mathrm{ml}$ and has been described fully elsewhere (Cloonan $e t$ al., 1976).

Approximately 1 hour before cardiac catheterisation each patient received an intramuscular injection of either diazepam $(0.14 \mathrm{mg} / \mathrm{kg})$ or papaveretum $(0.14 \mathrm{mg} / \mathrm{kg})$ and hyoscine hydrobromide $(0.03$ $\mathrm{mg} / \mathrm{kg}$ ). Most patients with valvular heart disease (22 of 30-Table 1) received in addition an intramuscular injection of crystalline penicillin ( 2 million units) 1 hour before and 6 hours after cardiac catheterisation. The catheter study was performed by one of three experienced cardiologists using either a right brachial vessel cut-down or a percutaneous right femoral puncture approach. The procedures undertaken are shown in Table 1. Indocyanine Green Dye USP ( $6 \mathrm{ml}$ injection) was used to measure cardiac output. The contrast material for angiography was Urografin 76 
Table 1 Diagnoses, premedication, and procedures undertaken, and incidence of myoglobinuria

\begin{tabular}{|c|c|c|c|}
\hline Variables & $\begin{array}{l}\text { No. of } \\
\text { patients }\end{array}$ & $\begin{array}{l}\text { No. } \\
\text { myoglobin } \\
\text { positive }\end{array}$ & $\%$ \\
\hline \multicolumn{4}{|l|}{ (1) Diagnosis } \\
\hline Normal & 25 & 4 & 16 \\
\hline Coronary artery disease & 92 & 28 & 30 \\
\hline Valvular heart disease & $30 *$ & $7 \dagger$ & 23 \\
\hline Miscellaneous & 11 & $4 \ddagger$ & 36 \\
\hline \multicolumn{4}{|l|}{$\begin{array}{l}\text { (2) Premedication } \\
\text { Papaveretum and hyoscine }\end{array}$} \\
\hline $\begin{array}{c}\text { Papaveretum and hyoscine } \\
\text { hydrobromide ( } \mathrm{P} \text { and } \mathrm{H})\end{array}$ & 89 & 31 & 34 \\
\hline Diazepam (D) & 54 & 8 & 15 \\
\hline Penicillin plus $P$ and $H$ or $D$ & 22 & 5 & 23 \\
\hline Other & 4 & 2 & 二 \\
\hline \multicolumn{4}{|l|}{ (3) Procedure } \\
\hline Cut-down & 136 & 35 & 26 \\
\hline Percutaneous & 19 & 3 & 16 \\
\hline Right heart catheter (RHC) only & 8 & 2 & 25 \\
\hline Left heart catheter (LHC) only & 10 & 4 & 40 \\
\hline RHC and LHC & 127 & 33 & 26 \\
\hline Selective coronary angiogram & 120 & 35 & 29 \\
\hline Aortogram & 15 & 3 & 20 \\
\hline Left ventricular angiogram & 130 & 35 & 27 \\
\hline Indocyanine green dye given & 91 & 33 & 36 \\
\hline Pulmonary angiogram & 3 & 2 & 一 \\
\hline Other & 7 & 1 & 14 \\
\hline
\end{tabular}

*Includes 12 with associated coronary artery disease.

†Includes 4 with associated coronary artery disease.

$¥$ Two patients with hypertrophic obstructive cardiomyopathy, 1 with a congestive cardiomyopathy and 1 with a conduction disturbance.

(Schering). We recorded the image intensification screening time required for each patient and used this to estimate the amount of catheter manipulation within the great arteries, veins, and the cardiac chambers during the procedure. The Sones technique was used for all coronary angiograms.

Twelve-lead electrocardiograms were performed routinely the day before and the day after cardiac catheterisation. In 45 of the 146 patients, serum creatine kinase and hydroxybutyrate dehydrogenase estimations were performed 24 to 30 hours before catheterisation and 18 to 24 hours after. Both were estimated kinetically at $37^{\circ} \mathrm{C}$ and $340 \mathrm{~nm}$ wave length using 'Calbiochem' reagents. 'Calbiochem' Stat-Pack (catalogue No. 869214) was used for creatine kinase. Student's $t$ test and $\chi^{2}$ analysis were used in the statistical calculations. Differences were accepted as significant when $P$ was less than 0.05 .

\section{Results}

Myoglobinuria was detected after cardiac catheterisation in $39(27 \%)$ of the 146 patients studied. It was not found in any of the patients during the 12-hour period before catheterisation, with one exception (see below). The distribution of the myoglobin-positive patients in relation to diagnosis, the intramuscular premedication given, the procedures undertaken, and the complications are shown in Tables 1 and 2.
Table 2 Complications after catheterisation and incidence of myoglobinuria

\begin{tabular}{|c|c|c|}
\hline \multirow[t]{2}{*}{ Complications } & \multicolumn{2}{|c|}{ No. of patients } \\
\hline & $\begin{array}{l}\text { Myoglobin } \\
\text { positive }\end{array}$ & $\begin{array}{l}\text { Myoglobin } \\
\text { negative }\end{array}$ \\
\hline Lost pulse/pulse problems & 1 & 5 \\
\hline Arrhythmia requiring treatment & 2 & 2 \\
\hline Hypotension requiring pressor agents & 0 & 2 \\
\hline Haematoma formation & 0 & 1 \\
\hline
\end{tabular}

There was a constant pattern of excretion in those patients with myoglobinuria. Fig. 1 illustrates this in one patient. Myoglobin was excreted in the first 7 urine samples passed during the first 18 hours after cardiac catheterisation but was not found thereafter. The small arrows indicate urine specimens in which myoglobin was not detected. This patient excreted a total of $30 \mathrm{mg}$ myoglobin.

In 34 of the 39 myoglobin-positive patients, myoglobin was detected in the first urine specimen after cardiac catheterisation; in the remaining 5 it was present for the first time in either the second or third post-catheter specimen. Once detected, myoglobin was present in all subsequent urine specimens for the next 3 to 22 hours (mean 11.8 hours). Excluding the one patient in whom myoglobinuria was detected before catheterisation, the mean amount of myoglobin excreted $\pm S E$ was $14.0 \pm 1.6 \mathrm{mg}$, with a range of 2.6 to $30.0 \mathrm{mg}$.

Fig. 2 shows the data obtained during two studies in one patient. The first study in this patient was incomplete. Right heart catheterisation was performed through a cut-down on the right brachial

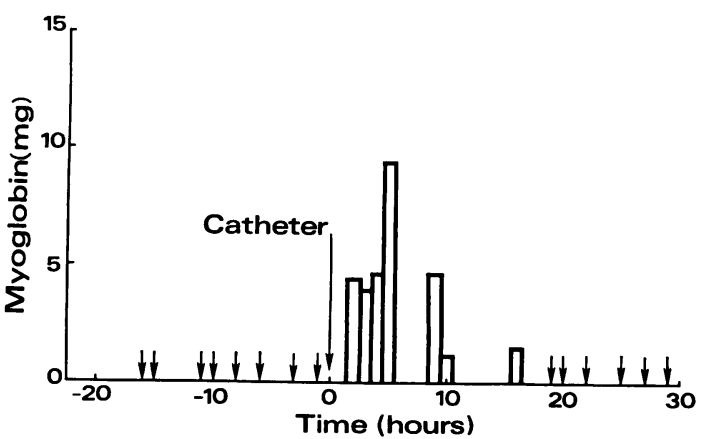

Fig. 1 Relation between amount of myoglobin excreted in each urine specimen and time before and after cardiac catheterisation (zero time) in one patient. Arrows indicate urine samples in which myoglobin was not detected. Myoglobin was detected in the first postcatheter urine specimen and in each subsequent specimen until 16 hours after catheterisation. In all, $30 \mathrm{mg}$ myoglobin was excreted. 


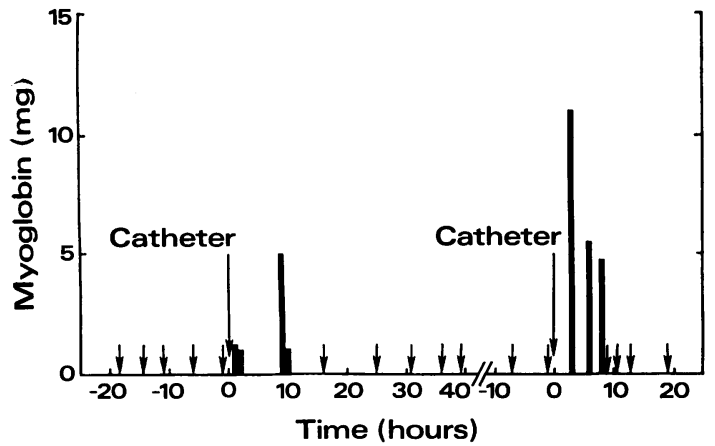

Fig. 2 Relation between amount of myoglobin excreted in each urine sample and time before and after cardiac catheterisation (zero time) in a patient who had two cardiac catheterisations within 3 days. Arrows indicate urine specimens in which myoglobin was not detected. Twelve milligrams of myoglobin were excreted after the first catheterisation and $25 \mathrm{mg}$ after the second (a more extensive study-see text).

vein. Left heart catheterisation and coronary angiography were attempted via a right brachial artery cut-down, but the study had to be abandoned because of technical difficulty experienced in passing the catheter from the right brachial artery into the ascending aorta. A right coronary artery angiogram only was performed, and $12 \mathrm{mg}$ myoglobin was excreted after this procedure (Fig. 2). A complete study was obtained 3 days later from the left arm using a brachial artery cut-down. The left heart was catheterised and left ventriculography as well as selective coronary angiograms and an aortogram were performed. This established that the patient had hypertrophic obstructive cardiomyopathy with moderate mitral and aortic regurgitation and normal coronary arteries. The screening time required was 29 minutes. After this second catheterisation $25 \mathrm{mg}$ myoglobin was excreted.

The screening time in the myoglobin-positive patients was $15.6 \pm 1.4$ minutes (mean \pm SE) whereas it was significantly less in those in whom it was not detected $(11.1 \pm 0.6$ minutes; $P<0.01)$.

From Table 1 it can be seen that the finding of myoglobinuria was not closely related to either diagnosis, the type of premedication, or the procedure undertaken. However, the incidence was highest in those patients with coronary artery disease whose studies routinely included a brachial artery cut-down, a combination of left and right heart catheterisation, coronary angiography, and left ventricular cine angiography. But there was no relation between the severity of coronary artery disease and the incidence of myoglobinuria among these 92 patients ( $\chi^{2}$ analysis). Eleven had less than 70 per cent obstructions of major coronary vessels and of these 3 had myoglobinuria; the other 81 patients had greater than 70 per cent obstructions and of the 24 with single vessel disease 9 had myoglobinuria, whereas 8 of the 26 with two vessel disease and 8 of the 31 with three vessel disease had myoglobinuria. Nor was there any significant relation between the amount of myoglobin excreted in the urine and the extent of coronary artery disease assessed by the number of vessels affected or myocardial function as judged by the ejection fraction measured from ventriculograms ( $\chi^{2}$ analysis).

In no patient was there any change in the electrocardiogram during the $\mathbf{4 8}$ hours after catheterisation to suggest evidence of cardiac muscle damage. The incidence of myoglobinuria was not influenced by the cardiologist performing the catheterisation $\left(\chi^{2}\right.$ analysis). It occurred in 10 of 45 patients $(22 \%)$ studied by the first, 17 of 62 patients studied by the second $(27 \%)$, and 10 of 30 patients studied by the third $(33 \%)$; the remaining 7 patients were studied by experienced fellows in cardiology and myoglobinuria occurred in $2(28 \%)$. In 6 of the 146 patients, diminished or transiently absent pulses occurred distal to the brachial artery cut-down. But of these, there was only one among the myoglobinpositive patients (see below); in the other 5 patients, myoglobinuria was not detected (Table 2). The other post-catheter complications did not occur more frequently in the myoglobin-positive patients (Table 2).

Among the 8 myoglobin-positive patients in whom pre- and post-catheterisation enzyme estimations were available, values for hydroxybutyrate dehydrogenase were the same-139 \pm 22 and $135 \pm$ $27 \mathrm{IU} /$ litre (means $\pm \mathrm{SE}$ ), respectively-while there was a small but statistically insignificant (paired $t$ test) increase in creatine kinase after catheterisation from $32 \pm 8$ to $51 \pm 16 \mathrm{IU} /$ litre (means $\pm \mathrm{SE}$ ) and with the small numbers there was no significant relation in individual patients between the change in creatine kinase and the amount of myoglobin excreted. The enzyme values before and after catheterisation in the myoglobinnegative patients were virtually identical for both enzymes measured.

The patient with pre-catheter myoglobinuria was a 68-year-old woman with severe aortic stenosis but without recent or past history of chest pain suggesting myocardial ischaemia. The pre-catheter urine sample was passed at 6.30 a.m. and contained $12.5 \mathrm{mg}$ myoglobin. She had had no intramuscular injections before this. The study confirmed the severity of the stenosis (calculated valve area = $0.5 \mathrm{~cm}^{2}$ ) and demonstrated obstructions high in the anterior descending branch of the left coronary 
artery $(90 \%)$ and in the middle third of the right coronary artery $(70 \%)$ with good left ventricular function. Screening time was $32 \frac{1}{2}$ minutes and, at the end, the right radial pulse was reduced, the pressure index (right radial divided by left radial systolic pressure) being $0 \cdot 68$. Exploration of the brachial artery was not thought to be indicated. She was not hypotensive at any time after catheterisation.

Myoglobin was detected in each of the first 5 post-catheter urine specimens passed, totalling in all $130 \mathrm{mg}$ myoglobin including the pre-catheter sample. It was not detected in subsequent urine samples. The pre-catheter electrocardiogram showed extreme left ventricular hypertrophy with symmetrical ST segment depression and $T$ wave inversion and was unaltered after catheterisation. Unfortunately, there were no measurements of pre- and post-catheterisation serum enzymes. At no time did she complain of pain suggesting myocardial ischaemia. Successful operation was later undertaken with replacement of the aortic valve and the insertion of a bypass graft to the left anterior descending coronary artery.

\section{Discussion}

So far as we are aware, this is the first report of myoglobinuria following cardiac catheterisation. Since myoglobin was detected in approximately 1 in every 4 patients submitted to this procedure, and the amounts excreted were substantial (mean $14.0 \mathrm{mg}$; range 2.6 to $30.0 \mathrm{mg}$ ), the mechanisms involved become particularly important.

As the method of measuring myoglobin in the urine does not distinguish between that of cardiac or skeletal muscle origin, myoglobin could have been released from either or from both types of muscle. It seems unlikely that intramuscular injections given as premedication contributed to the myoglobin release. This possibility was explored fully during an earlier study in which 15 patients were given intramuscular injections similar to those in the present study. The same method for estimating myoglobin was used and in no patient was myoglobinuria detected (Cloonan et al., 1976). Moreover, in the present study, the incidence of myoglobinuria in the patients with valvular heart disease tended to be relatively low (see Table 1) despite these patients receiving intramuscular injections of 2 million units of penicillin 1 hour before and 6 hours after the procedure in addition to routine premedication. We concluded, therefore, that muscle damage resulting from intramuscular injections was not responsible for the myoglobinuria. Skeletal muscle ischaemia secondary to vessel occlusion by catheters may have been a factor even though transient loss or reduction of the radial pulse after the procedure occurred in only one myoglobinpositive patient whereas this was seen in 5 patients negative for myoglobinuria. Furthermore, no episodes of hypotension or haematoma formation were recorded in the myoglobin-positive group whereas there were 2 of the former and 1 of the latter among the negative patients (Table 2). It is quite likely, therefore, that the myoglobin was partly or wholly of cardiac origin. Heart muscle has a much higher myoglobin content than does skeletal muscle (Kagen, 1973).

Myoglobin is a relatively small molecule (molecular weight 17000 ), much smaller than the enzymes commonly used as indicators of myocardial damage, and it may move more easily through damaged cell membranes than, for example, creatine kinase or hydroxybutyrate dehydrogenase. It is noteworthy that myoglobinuria was detected principally in patients with ischaemic heart disease who had coronary and left ventricular angiograms and that, as a group, the myoglobin-positive patients required significantly longer screening time to complete the procedures undertaken. This suggested that the presence and magnitude of myoglobinuria was related to the length of the procedure and to the amount accomplished during it. Thus, myoglobin of cardiac origin could have resulted from endocardial trauma by catheters, high pressure injections of contrast material, or from brief myocardial ischaemia caused by catheter occlusion of coronary arteries or dye-filled coronary arteries. Furthermore, it is possible that radio-opaque dye in coronary arteries causes transient cell membrane dysfunction leading to leakage of myoglobin from the cell. We have no explanation for the recent data of Stone and his associates (Stone et al., 1977) who reported no significant increase in serum myoglobin levels in 9 patients after cardiac catheterisation. But, in view of the incidence of myoglobinuria we found $(27 \%)$, changes may have been seen if more patients had been studied.

A number of authors have described an increase in serum enzyme activity-principally of creatine kinase-in a proportion of patients after cardiac catheterisation (Marpole et al., 1968; Michie et al., 1970; Chahine et al., 1974). In the present study there was a small increase in creatine kinase in the 8 myoglobin-positive patients for whom measurements were available-from $32 \pm 8$ to $51 \pm 16$ $\mathrm{IU} /$ litre (means $\pm \mathrm{SE}$ ). However, with these small numbers the difference was not statistically significant; nor was there a relation in individual patients between the change in creatine kinase and the amount of myoglobin excreted. Nevertheless, it 
may be relevant that no increase in creatine kinase occurred in the larger number (35) of myoglobinnegative patients for whom there were enzyme measurements.

There is dispute on the origin of increased postcatheter creatine kinase. Roberts and his associates (Roberts et al., 1975) measured serum activity before and after cardiac catheterisation of total creatine kinase as well as its $\mathrm{MB}$ isoenzyme which is found primarily in heart muscle. While peak total serum creatine kinase increased after catheterisation, the $M B$ isoenzyme activity remained within normal limits. They concluded that the increase was not of cardiac origin.

However, in a recent study, Hori and his associates (Hori et al., 1976) described differences in total serum creatine kinase increases after catheterisation between patients who did and did not have selective coronary angiography and reported further that the patients with more extensive coronary vascular disease produced larger increases in serum creatine kinase after catheterisation. Our data are not in accordance with the latter observation in that in our study the extent of coronary vascular disease and variations in ejection fraction did not correlate with the amount of myoglobin excreted. Hori and his associates (Hori et al., 1976) suggested that the raised levels represented some form of myocardial damage which is much less than that seen during acute myocardial infarction. In this context, the total amount of myoglobin excreted in the present study-14.0 $\pm 1.6 \mathrm{mg}$-was considerably less than the $50.7 \pm 9.4 \mathrm{mg}(P<0.001)$ we obtained recently in 14 patients with uncomplicated acute myocardial infarction; and this latter amount was undoubtedly an underestimation since in 2 of the 14 patients the end-point of the excretion phase was not determined (Donald et al., 1977). There is, therefore, probably about a fourfold difference in excretion in the two situations. Roberts and his associates (Roberts et al., 1975) found a similar difference in serum creatine kinase enzyme activity after catheterisation and myocardial infarction. Since MB isoenzyme activity is only about 10 per cent of total activity the expected increase in the MB isoenzyme after catheterisation would be small if the creatine kinase increase were partly or wholly of cardiac origin. This might not be detected by comparing group mean values which could still remain within the normal range.

In the extreme case in the present series of the patient with pre-catheter myoglobinuria, we concluded that the large amount she excreted$130 \mathrm{mg}$ - was almost certainly largely of cardiac origin. In an earlier study (Cloonan et al., 1976) we examined random urine samples in 146 control patients. Only 4 were positive for myoglobinuria and each had an adequate medical or surgical reason for skeletal muscle damage to explain this. Our present patient had critical aortic stenosis with paroxysmal nocturnal dyspnoea, a haemodynamic situation likely to produce subendocardial ischaemia (Buckberg et al., 1972). She had, furthermore, 70 per cent and 90 per cent obstructions in two of her three main coronary arteries. We suggest that, before catheterisation, she had undetected subendocardial ischaemia with release of myoglobin which became accentuated as a result of cardiac catheterisation and selective coronary angiography. Though she did have a reduced radial pulse after the procedure, this was also noted in 5 other patients in the series and all were myoglobin-negative. The amount of myoglobinuria in this patient was of a similar order to that we have found in some patients with acute myocardial infarction (Donald et al., 1977).

In conclusion, we found substantial myoglobinuria in approximately 1 in 4 patients coming to routine cardiac catheterisation. It is considered likely that at least some of this myoglobin was of myocardial origin, and was related to transient and presumably completely reversible cardiac injury occurring during catheterisation and selective angiography. It seems prudent to maintain a continuing vigilance in assessing the indications for cardiac catheterisation, particularly in those patients with ischaemic heart disease in whom coronary angiography is contemplated.

We thank Dr David Brender for reviewing the manuscript. This work was supported in part by a grant from the National Heart Foundation of Australia.

\section{References}

Buckberg, E. D., Foxler, D. E., Archie, J. P., and Hoffman, J. I. E. (1972). Experimental subendocardial ischemia in dogs with normal coronary arteries. Circulation Research, 30, 67-81.

Chahine, R. A., Eber, L. M., and Kattus, A. A. (1974). Interpretation of the serum enzyme changes following cardiac catheterization and coronary angiography. American Heart fournal, 87, 170-174.

Cloonan, M. J., Donald, T. G., Neale, C., and Wilcken, D. E. L. (1976). The detection of myoglobin in urine and its application to the diagnosis of myocardial infarction. Pathology, 8, 313-320.

Donald, T. G., Cloonan, M. J., Neale, C., and Wilcken, D. E. L. (1977). The excretion of myoglobin in the urine after acute myocardial infarction. British Heart fournal, 39, 29-34.

Hori, M., Inoue, M., Fukui, S., Furukawa, T., Abe, H., Minamino, T., and Ohgitani, N. (1976). Significance of serum enzyme changes after cardiac catheterisation and selective coronary arteriography. British Heart fournal, 38, 97-103.

Kagen, L. J. (1973). Myoglobin: Biochemical, Physiological and Clinical Aspects. Columbia University Press, New York. 
Marpole, D., Judkins, W., Kloster, F., Marquardt, V., and Griswold, H. (1968). Elevated serum enzymes following coronary angiography (abstract). Circulation, 37 and 38, Suppl. VI, 134.

Michie, D. D., Conley, M. A., Carretta, R. F., and Booth, R. S. (1970). Serum enzyme changes following cardiac catheterizations with and without selective coronary arteriography. American fournal of the Medical Sciences, 260, 11-20.

Roberts, R., Ludbrook, P. A., Weiss, E. S., and Sobel, B. E. (1975). Serum CPK isoenzymes after cardiac catheterization. British Heart fournal, 37, 1144-1149.
Stone, M. J., Waterman, D., Harimoto, D., Murray, G., Willson, N., Platt, M. R., Blomqvist, G., and Willerson, J. T. (1977). Serum myoglobin level as diagnostic test in patients with acute myocardial infarction. British Heart Fournal, 39, 375-380.

Requests for reprints to Dr D. E. L. Wilcken, Department of Medicine, Clinical Sciences Building, Prince Henry Hospital, Little Bay, N.S.W. 2036, Australia. 